\title{
Malaria Surveillance at the Patent Medicine Vendors: A Pilot Study in Jigawa State, Nigeria
}

\author{
Jalal-Eddeen Abubakar Saleh"1 ${ }^{*}$, Abdullahi Saddiq1, Rex Mpazanje1, Lynda Ozor', \\ Umar Garba Bulangu², Seye Babatunde1, Ini Nglass', Edwin Edeh', Nura Shuaib1, \\ Moses Onoh ${ }^{1}$
}

${ }^{1}$ Communicable and Non-Communicable Diseases Cluster, World Health Organization, Abuja, Nigeria

${ }^{2}$ Public Health Department, Jigawa State Ministry of Health, Jigawa State, Nigeria

Email:*salehj@who.int

How to cite this paper: Saleh, J.-E.A., Saddiq, A., Mpazanje, R., Ozor, L., Bulangu, U.G., Babatunde, S., Nglass, I., Edeh, E., Shuaib, N. and Onoh, M. (2020) Malaria Surveillance at the Patent Medicine Vendors: A Pilot Study in Jigawa State, Nigeria. Open Access Library Journal, 7: e6641.

https://doi.org/10.4236/oalib.1106641

Received: July 22, 2020

Accepted: September 26, 2020

Published: September 29, 2020

Copyright $\odot 2020$ by author(s) and Open Access Library Inc.

This work is licensed under the Creative Commons Attribution International License (CC BY 4.0).

http://creativecommons.org/licenses/by/4.0/

\begin{abstract}
Background: In Nigeria, the 2018 world malaria report shows that the country's malaria surveillance system detects less than 20 per cent of the total malaria case. In malaria control programmes, the main source of data is health facility-based and reported routinely through the health information systems. The collected data is mainly for monitoring and evaluation at the programmatic level. Although the adoption of the District Health Information Software (DHIS2) has greatly improved the availability of routine data from health facilities, much is being missed out in the developing countries. And this is because a sizeable number of malaria cases ends up at the formal and non-formal patent medicine vendors (PMVs), thus raising questions about the representativeness of the data collected through the routine DHIS2. Methods: This pilot study, using a quantitative cross-sectional study, attempted to assess malaria surveillance at the PMVs. Three local government areas (LGAs) of Jigawa state, northwestern Nigeria were randomly selected at one LGA from each of the three senatorial districts of the state. Using SPSS statistical application version 24 , the study looked at suspected malaria cases across the LGAs. Also, it assessed causal relationships between the RDT testing for suspected malaria and treatment using the ACTs at the PMVs. The eligible participants were children and adults across the two genders with suspected malaria using fever as the entry point. The study collected data for suspected malaria cases between 1st September and 30th November 2019. Results: The analyses show that a total of 9080 suspected fever cases reported in 22 wards across the 3 selected LGAs (Dutse, Ringim, and Kafin Hausa). The disaggregated data shows Dutse reported 2328 (25.64\%), Ringim 3515 (38.71\%), and
\end{abstract}


K/Hausa 3237 (35.65\%) cases. The Pearson Correlation 1.000, $(\alpha=0.01, \mathrm{p}<$ $0.05)$ 2-tailed test showed a positive linear relationship between suspected malaria cases at the PMVs who get mRDT test and treatment using the ACTs. The Null Hypothesis, which stated that there is no correlation between ACT treatment and suspected malaria cases at the patent medicine vendors (PMVs) tested using mRDT, was rejected in favor of the Alternative Hypothesis. Conclusion: This study underscores the need for malaria control programmes at all levels to incorporate the PMVs in the routine reporting system through the DHIS2 platform. This approach would go a long way to improve the country's malaria surveillance system, channel the meagre resources to effectively reduce malaria morbidity and mortality, and help in attaining the malaria-free status.

\section{Subject Areas}

Epidemiology, Infectious Diseases

\section{Keywords}

Malaria Elimination, Patent Medicine Vendors, mRDT, ACT, Jigawa, Suspected Fever, Nigeria

\section{Background}

In malaria control programmes, design and implementation require information on the number and distribution of malaria cases and deaths [1]. This strategy aims to determine which areas or population groups that are most affected by the disease, so that resources can be targeted to the populations most in need. Similarly, this approach would help to know the disease incidence in relation to past levels to alert control programmes about possible epidemics for additional control measures to be instituted [1]. The principle objectives of Malaria surveillance systems are to provide programme managers with information to identify geographical locations and population groups in which the incidences of malaria cases and deaths are the greatest and to track changes in the incidence of malaria cases and deaths over time [2].

It is important that National Malaria Control Programmes (NMCP) pay particular attention to ensuring that all private and public health facilities and Community Health Workers (CHWs) report accurately and on time and should have an up-to-date inventory of all the public and other health facilities that are expected to submit reports if there are any delays they should be followed up [3]. This is particularly critical since cases reported to malaria surveillance systems represent an incomplete sample of all patients with fever or malaria. In most malaria-endemic countries, less than half of all patients with fever cases attend public health facilities, thus, not only do health facility surveillance reports 
represent only a fraction of all fever and malaria cases occurring in the community, but they may also represent a biased sample, in that health facility attendees may live closer to the facilities and have better access to medicines and a range of government services and economic opportunities [2].

Although the adoption of the District Health Information Software (DHIS2) has greatly improved the availability of routine data from health facilities, much is being missed out in the developing countries because a sizeable number of malaria cases end up at the formal and non-formal patent medicine vendors (PMVs), thus raising questions about the representativeness of the data collected through the routine DHIS2 [4]. Private sector's role in malaria surveillance raises challenges, but it has room for improvement because it is important, for instance, malaria treatment, and acting as an effective drug distribution channel to remote, rural areas [5]. In rural Nigeria about $60 \%$ of mothers prefer to consult Patent medicine Vendors (PMVs) rather than other providers for treatment of childhood malaria [1]. PMVs are a large group of informal private health providers found in many countries who operate as shop keepers, traders in periodic markets, itinerant drug peddlers, and wholesale drug merchants [6]. PMVs will continue to play a major role in malaria treatment especially those in the rural areas where the burden of malaria is higher [7]. More so, since they are readily available and their services tend to be cheaper on the short run due to non-payment of consultation fees and reduced transport costs [8], the PMVs would continue to play a dominant role especially in the rural settings.

The research question, null and alternative hypotheses, for this study are:

RQ: Does suspected malaria clients who go to the patent medicine vendors (PMVs) get tested using mRDTs before treatment with ACTs?

Ho: There is no correlation between ACT treatment and suspected malaria cases at the patent medicine vendors (PMVs) tested using mRDT.

Ha: There is a correlation between ACT treatment and suspected malaria cases at the patent medicine vendors (PMVs) tested using mRDT.

The dependent variable (DV) was treatment using ACTs and the independent variable (IV) was mRDT test at the PMVs.

\section{Methods}

\subsection{Purpose}

It has been shown that the Nigerian malaria surveillance system detects less than 20 per cent of the total malaria case [9]. The overall purpose and intention of this study was to establish that several malaria cases go to the patent medicine vendors (PMVs) for treatment and that some of the PMVs do carryout mRDT test on the patients before treatment using ACTs. The outcome of this study will support the fact that several malaria cases end up getting treated at the PMVs, and this explains the reasons for the failure of Nigeria's surveillance to report the majority of malaria cases, which potentially could affect meeting the GTS 2030 milestones. 


\subsection{Theoretical and Conceptual Framework}

The theoretical framework used in this study was the theory of planned behavior (TPB). The TPB was meant to be applied to the prediction of purely volitional behaviors, and to help understand psychological determinants of individuals [10] [11].

The TPB as a theoretical framework has been applied in predicting a wide range of different human behaviors. This theory uses three predictors: attitude, subjective norm and perceived behavioral control, to show that human behavior is dependent on the intention to perform the behavior [11]. Applying TPB to a predictive model of malaria, there are various determinants of preventive behavioral intention of people towards malaria. The beliefs of people on the outcomes of their febrile illness after they attend PMVs, on getting tested with the mRDTs before getting treated using the ACTs; and this also determine the attitudes of the clients toward receiving and using malaria preventive measures against the disease.

\subsection{Data Collection and Analysis}

This quantitative cross-sectional study, attempted to assess malaria surveillance at the PMVs. The study collected data for suspected malaria cases at the PMVs between $1^{\text {st }}$ September and $30^{\text {th }}$ November 2019 across three local government areas (LGAs) in Jigawa state, northwestern Nigeria. These months reflect the end of high transmission and the beginning of low transmission seasons. Given that fever is the entry point, the inclusion and exclusion criteria are - any patients who present to the PMVs with a complaint of fever and any patients who did not have a fever, respectively. The LGAs were line listed based on their senatorial zones and one randomly selected from each zone: Dutse (north), Ringim (west), and Kafin Hausa (east). To facilitate the data collection process in the selected LGAs, three officers were recruited, trained centrally and deployed accordingly. The data for the study were cleaned and stored in a database and used in accordance with the acceptable standard research procedural guidelines.

The analyses show that a total 9080 suspected fever cases were seen in 22 wards across the 3 selected LGAs (Dutse, Ringim, and Kafin Hausa). The disaggregated data shows Dutse reported 2328 (25.64\%), Ringim 3515 (38.71\%), and K/Hausa 3237 (35.65\%) cases (Figure 1).

As shown in Figure 1, K/Hausa reported their highest number of cases in September (2285), while Ringim (1340) and Dutse (1121) had their highest reported fever cases in the month of October. However, and despite of the number of fever cases reported, the proportion of those tested using mRDT was much less in each of the three LGAs. K/Hausa LGA tested 10 per cent of the fever cases in September and 6 per cent in October and November respectively. Similarly, the picture is not much different in the other two LGAs.

Figure 2 shows fever cases tested using mRDT in under 5 and above 5 years across the three LGAs. It is clear from the chart that K/Hausa had more under 


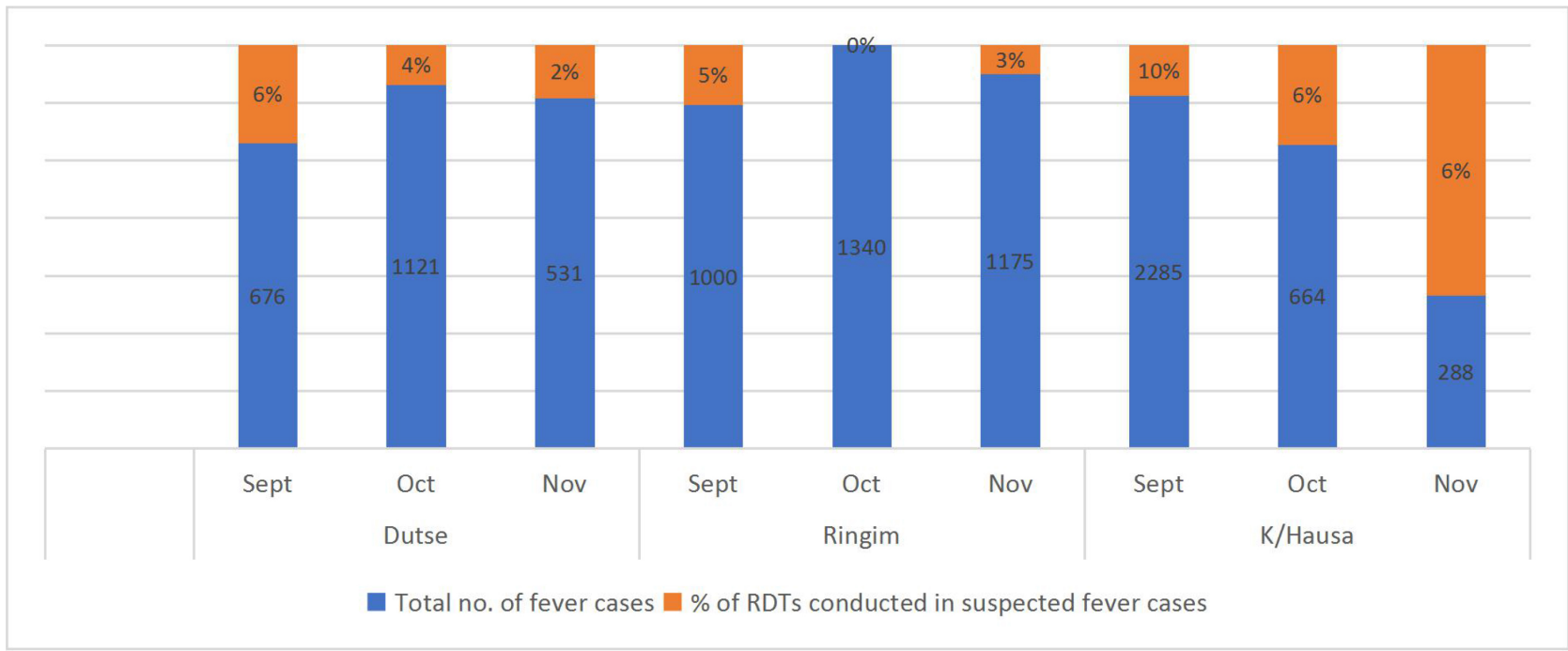

Figure 1. Showing Bar Chart of suspected fever cases between September-November 2019 across the LGAs.

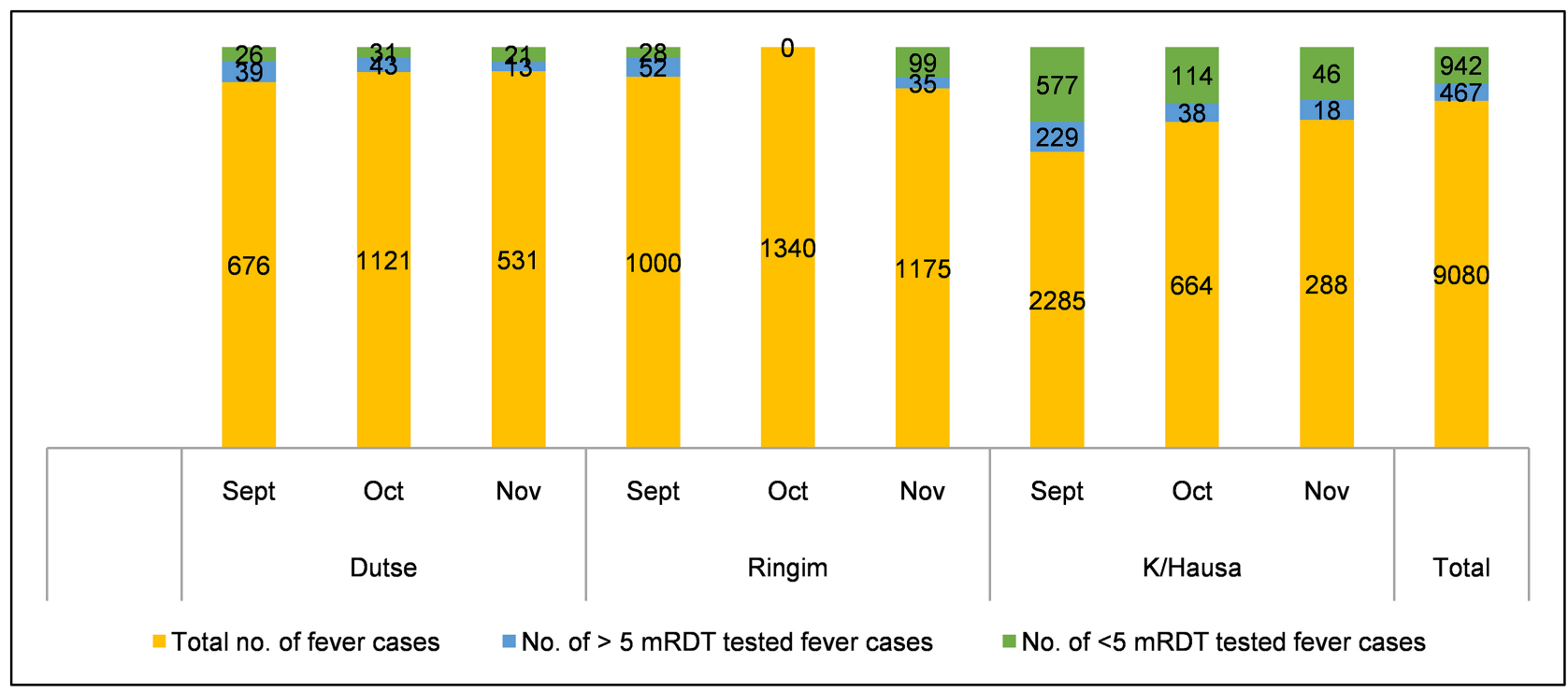

Figure 2. Showing comparison of fever cases tested using mRDT in under 5 and above 5 years across the LGAs.

5 years tested than those above 5 years. This high number was attributed to more caregivers requesting for mRDT tests to be conducted on their under 5-children than in the other two LGAs.

Looking at the PMVs that had IEC materials displayed in their shops, K/Hausa had the highest number while Ringim had the lowest (Figure 3). The availability of displayed IEC materials in the PMVs would help in creating awareness to the caregivers on the available malaria interventions and strategies used in malaria prevention and control.

From Figure 4, it is encouraging to note that all the PMVs treat any positive fever cases using the recommended ACTs. This practice is, indeed, commendable, especially that malaria-endemic countries are making efforts to reach the malaria-free status. 


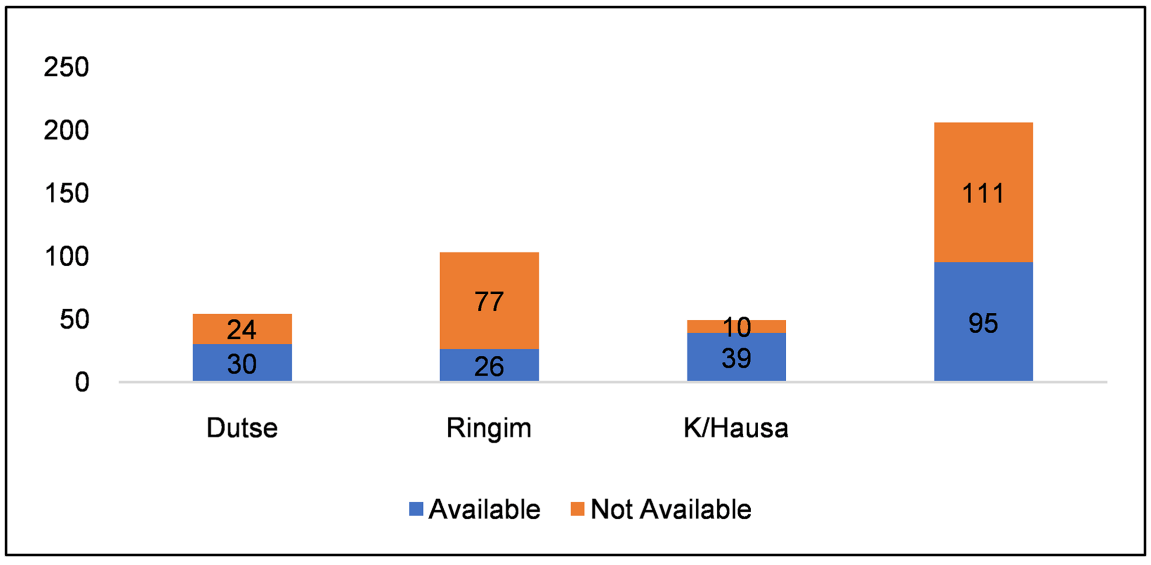

Figure 3. Shows availability of IEC materials at the PMVs.

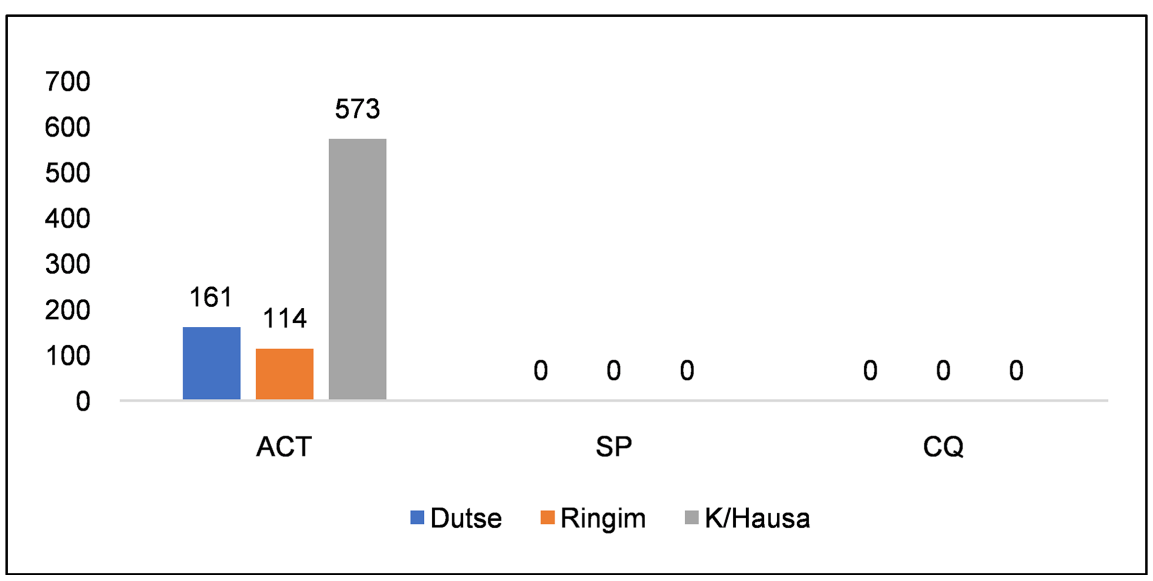

Figure 4. Shows the type of treatment given to fever positive cases by PMVS across the LGAs.

\subsection{Statistical Methods}

The analyses of the collected data were done using SPSS (version 24). The SPSS statistical application would be used to assess causal relationships between the RDT testing for suspected malaria and treatment using the ACTs at the PMVs.

In this study, the Null Hypothesis states that there is no correlation between ACT treatment and suspected malaria cases at the patent medicine vendors (PMVs) tested using mRDT, while the Alternative hypothesis states that there is a correlation between ACT treatment and suspected malaria cases at the patent medicine vendors (PMVs) tested using mRDT.

The scatterplot in Figure 5 shows a positive linear relationship between suspected malaria cases at the PMVs who get mRDT test and treatment using the ACTs. This significant correlation is further supported by the Pearson Correlation 1.000, $(\alpha=0.01, \mathrm{p}<0.05)$ 2-tailed test (Table 1).

Therefore, the Null Hypothesis, which stated that there is no correlation between ACT treatment and suspected malaria cases at the patent medicine vendors (PMVs) tested using mRDT, was rejected in favour of the Alternative Hypothesis. 
Simple Scatter with Fit Line of ACTs treatment to positives by mRDT positives

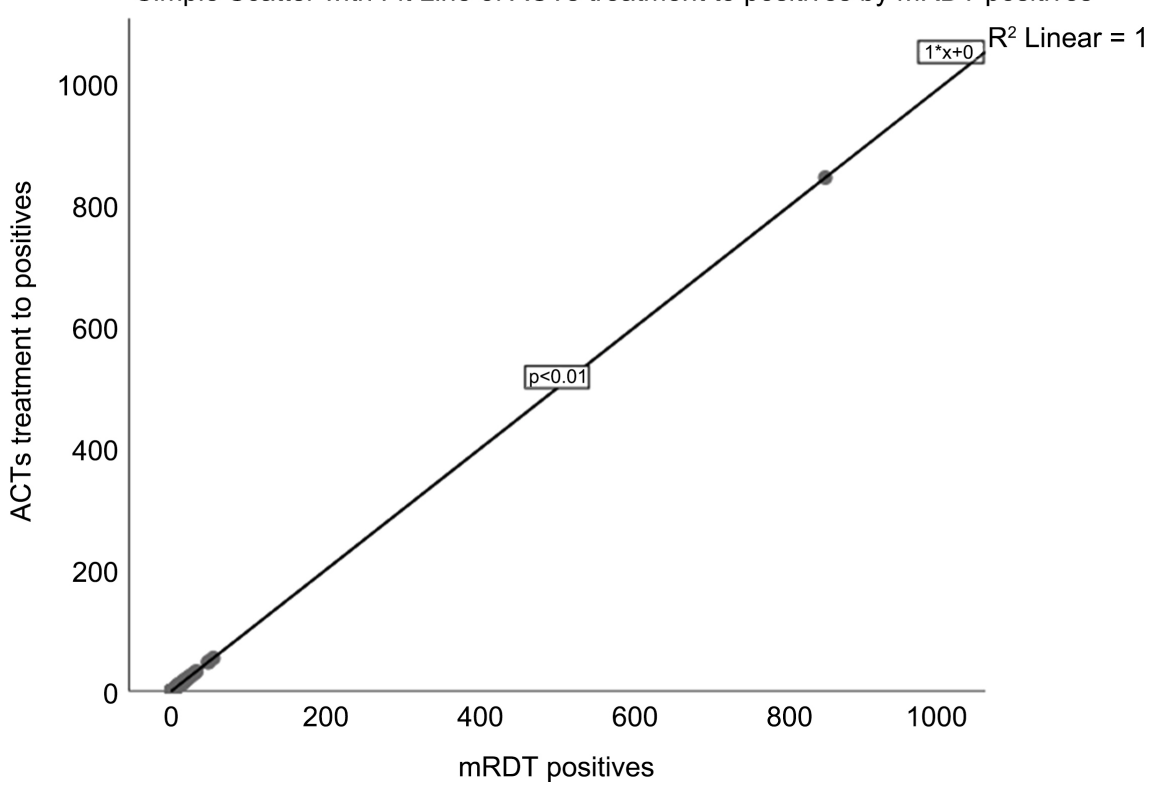

Figure 5. Showing Scatter Plot of mRDT positives versus ACT treatment.

Table 1. Showing Pearman's Correlation between mRDT positives and ACT treatment.

\begin{tabular}{|c|c|c|c|c|}
\hline \multicolumn{5}{|c|}{ Correlations } \\
\hline & & & mRDT positives & $\begin{array}{l}\text { ACTs treatment } \\
\text { to positives }\end{array}$ \\
\hline \multirow{6}{*}{ Kendall's tau_b } & \multirow{3}{*}{ mRDT positives } & Correlation Coefficient & 1.000 & $1.000^{* *}$ \\
\hline & & Sig. (2-tailed) & . & . \\
\hline & & $\mathrm{N}$ & 192 & 192 \\
\hline & \multirow{3}{*}{$\begin{array}{l}\text { ACTs treatment } \\
\text { to positives }\end{array}$} & Correlation Coefficient & $1.000^{* *}$ & 1.000 \\
\hline & & Sig. (2-tailed) & . & . \\
\hline & & $\mathrm{N}$ & 192 & 192 \\
\hline \multirow{6}{*}{ Spearman's rho } & \multirow{6}{*}{$\begin{array}{l}\text { ACTs treatment } \\
\text { to positives }\end{array}$} & Correlation Coefficient & 1.000 & $1.000^{* *}$ \\
\hline & & Sig. (2-tailed) & . & . \\
\hline & & $\mathrm{N}$ & 192 & 192 \\
\hline & & Correlation Coefficient & $1.000^{* *}$ & 1.000 \\
\hline & & Sig. (2-tailed) & . & . \\
\hline & & $\mathrm{N}$ & 192 & 192 \\
\hline
\end{tabular}

${ }^{* *}$ Correlation is significant at the 0.01 level (2-tailed).

\section{Discussion}

It is clear from the outcome of this study that the majority of suspected fever cases, which are not officially capture through the routine reporting channel, ends up at the patent medicine vendors. The data collected during this pilot study reveal that over 9000 suspected fever cases were seen at PMVs across the 22 wards of the three pilot LGAs over the three-month period. It is clear that 
people, especially the poor and those in the rural communities, find the PMVs readily accessible and affordable much more than public health centres [12] [13] [14] [15] [16]. Similarly, the operators of the PMVs, who are often community health extension workers (CHEWS), not only treat the patients but also offer health advice and with home visits where necessary [14]-[20]. The malaria data from the PHCs and some few secondary, tertiary, and recently private health facilities are warehoused in the DHIS2; this reporting system misses out a large number of cases that ends up at the PMVs [4].

The Null Hypothesis in this study, which stated that there is no correlation between ACT treatment and suspected malaria cases at the patent medicine vendors (PMVs) tested using mRDT, was rejected in favour of the Alternative hypothesis. The analysis shows a strong correlation between the two as supported by the Pearson Correlation 1.000, $(\alpha=0.01, p<0.05), 2$-tailed test.

There is a need to underscore that between $15 \%-82 \%$ of caregivers in sub-Saharan Africa seeks for treatment of their sick children at the PMVs [14] [21]. Studies have shown that nearly 1.3 billion people across the globe lack access to quality healthcare and this is attributed to weak healthcare financing systems operating especially in the developing countries [24]. Furthermore, the health systems in the developing countries are funded mostly through inequitable forms of health financing the out-of-pocket (OOP) payments, contributing to household poverty and creating a barrier to accessing quality healthcare services [22]-[28]. Similarly, if this huge and mostly unregulated PMVs would be incorporated into the formal reporting system, this would improve on malaria surveillance and contribute to national child survival initiatives [4] [21].

\section{Conclusion}

This study underscores the need for malaria control programmes at all levels to incorporate the PMVs in the routine reporting system through the DHIS2 platform. This approach would go a long way to improve the country's malaria surveillance system, channel the meagre resources to effectively reduce malaria morbidity and mortality, and help in attaining the malaria-free status.

\section{Limitations}

This study was limited because some PMV owners were reluctant to open up to the data collectors on the use of RDTs and ACTs to test and treat their clients out of fear of probing further on how they obtained the test kits and the drugs.

\section{Data Availability}

All data have been summarized and presented in the manuscript. The data cannot be deposited to any external agency because of policy and other restrictions.

\section{Ethical Issues/Protection of Participants Rights}

The pilot study, conducted by the World Health Organization, is part of the 
Technical Assistance given to the state and national malaria elimination programme in Nigeria. Approval for the pilot of this study was obtained from the state ministry of health. To ensure confidentiality, no person or shop was identified by name.

\section{Conflicts of Interest}

The authors of this report declare that no funding was received, no potential conflict of interest or any royalty associated.

\section{References}

[1] WHO (2012) Disease Surveillance for Malaria Control: An Operational Manual.

[2] WHO (2006) Partnerships for Malaria Control: Engaging the Formal and Informal Private Sectors. Geneva.

[3] UNICEF (2015) Achieving the Malaria MDG Target. https://www.unicef.org/reports/achieving-malaria-mdg-target

[4] Githinji, S., Oyando, R., Malinga, J., et al. (2017) Completeness of Malaria Indicator Data Reporting via the District Health Information Software 2 in Kenya, 2011-2015. Malaria Journal, 16, 344. https://doi.org/10.1186/s12936-017-1973-y

[5] Berendes, S., Adeyemi, O., Oladele, E.A., Oresanya, O.B., et al. (2012) Are Patent Medicine Vendors Effective Agents in Malaria Control? Using Lot Quality Assurance Sampling to Assess Quality of Practice in Jigawa, Nigeria. PLoS ONE, 7 , e44775. https://doi.org/10.1371/journal.pone.0044775

[6] Akuse, R.M., Eseigbe, E.E., Ahmed, A. and Brieger, W.R. (2010) Patent Medicine Sellers: How Can They Help Control Childhood Malaria? Malaria Research and Treatment, 2010, Article ID: 470754. https://doi.org/10.4061/2010/470754

[7] WHO (2018) Malaria Surveillance, Monitoring \& Evaluation: A Reference Manual.

[8] Benjamin, S.C., Uzochukwu, O.P., Emma-Ukaegbu, E.U., Onwujekwe, O.E., et al. (2010) Malaria Treatment Services in Nigeria: A Review. Nigerian Medical Journal, 51, 114-119.

[9] WHO (2018) World Malaria Report 2018. https://www.who.int/malaria/publications/world-malaria-report-2018/en

[10] Ajzen, I. and Fishbein, M. (1980) Understanding Attitudes and Predicting Social Behavior. Prentice-Hall, Englewood Cliffs.

[11] Glanz, K., Rimer, B.K. and Viswanath, K. (2008) Health Behavior and Health Education: Theory, Research, and Practice. 4th Edition, John Wiley and Sons, San Francisco.

[12] Salako, L.A., Brieger, W.R., Afolabi, B.M., et al. (2001) Treatment of Childhood Fevers and Other Illnesses in Three Rural Nigerian Communities. Journal of Tropical Pediatrics, 47, 230-238. https://doi.org/10.1093/tropej/47.4.230

[13] Snow, R.W., Peshu, N., Forster, D., Mwenesi, H. and Marsh, K. (1992) The Role of Shops in the Treatment and Prevention of Childhood Malaria on the Coast of Kenya. Transactions of the Royal Society of Tropical Medicine and Hygiene, 86, 237-239. https://doi.org/10.1016/0035-9203(92)90290-S

[14] Goodman, C., Brieger, W., Unwin, A., Mills, A., Meek, S. and Greer, G. (2007) Medicine Sellers and Malaria Treatment in Sub-Saharan Africa: What do They Do and How Can Their Practice Be Improved? The American Journal of Tropical 
Medicine and Hygiene, 77, 203-218. https://doi.org/10.4269/ajtmh.2007.77.203

[15] van der Geest, S. (1987) Self-Care and the Informal Sale of Drugs in South Cameroon. Social Science and Medicine, 25, 293-305. https://doi.org/10.1016/0277-9536(87)90232-2

[16] Onwujekwe, O. (2005) Inequities in Healthcare Seeking in the Treatment of Communicable Endemic Diseases in Southeast Nigeria. Social Science and Medicine, 61, 455-463. https://doi.org/10.1016/j.socscimed.2004.11.066

[17] Strategies for Enhancing Access to Medicines (SEAM) - in Proceedings of the Targeting Improved Access to Essential Medicine Conference, Accra, Ghana, June 2005.

https://www.msh.org/news-events/stories/improving-access-to-medicines-for-all

[18] Brugha, R. and Zwi, A. (1998) Improving the Quality of Private Sector Delivery of Public Health Services: Challenges and Strategies. Health Policy and Planning, 13, 107-120. https://doi.org/10.1093/heapol/13.2.107

[19] Raynal, A.L. (1985) Use of Over-the-Counter Medications in Rural Matabeleland, Zimbabwe: The Case for Upgrading the Dispensing Skills of Rural Storekeepers. Central African Journal of Medicine, 31, 92-97.

[20] Oshiname, F.O. and Brieger, W.R. (1992) Primary Care Training for Patent Medicine Vendors in Rural Nigeria. Social Science and Medicine, 35, 1477-1484. https://doi.org/10.1016/0277-9536(92)90050-Z

[21] Tawfik, Y., Northrup, R. and Prysor-Jone, S. (2002) Utilizing the Potential of Formal and Informal Private Practitioners in Child Survival: Situation Analysis and Summary of Promising Interventions. Tech. Rep., Support for Analysis and Research in Africa (SARA) Project, Academy for Educational Development, Washington DC. http://pdf.usaid.gov/pdf docs/PNACP202.pdf

[22] Adinma, E.D. and Adinma, B.J. (2010) Community Based Healthcare Financing: An Untapped Option to Effective Healthcare Funding in Nigeria. Nigerian Medical Journal, 51, 95-100.

[23] Sekhri, N. and Savedoff, W. (2005) Private Health Insurance: Implications for Developing Countries. Bulletin of the World Health Organization, 83, 127-134.

[24] Carrin, G., Mathauer, I., Xu, K. and Evans, D.B. (2008) Universal Coverage of Health Services: Tailoring Its Implementation. Bulletin of the World Health Organization, 86, 857-863. https://doi.org/10.2471/BLT.07.049387

[25] Evans, D.B., Carrin, G. and Evans, T.G. (2005) The Challenge of Private Insurance for Public Good. Bulletin of the World Health Organization, 83, 83.

[26] Preker, A.S., Carrin, G., Dror, D., Jakab, M., Hsiao, W. and Arhin-Tenkorang, D. (2002) Effectiveness of Community Health Financing in Meeting the Cost of Illness. Bulletin of the World Health Organization, 80, 143-150.

[27] Poletti, T., Balabanova, D., Ghazaryan, O., Kamal-Yanni, M., Kocharyan, H., Arakelyan, K. and Hakobyan, M. (2007) Options for Scaling Up Community-Based Health Insurance for Rural Communities in Armenia. Health Systems Development. London School of Hygiene and Tropical Medicine, London.

[28] Polonsky, J., Balabanova, D., McPake, B., Poletti, T., Vyas, S., Ghazaryan, O. and Yanni, M.K. (2009) Equity in Community Health Insurance Schemes: Evidence and Lessons from Armenia. Health Policy Plan, 24, 209-216.

https://doi.org/10.1093/heapol/czp001 